OPEN ACCESS

Edited by:

Rick M. Dijkhuizen,

University Medical Center

Utrecht, Netherlands

Reviewed by:

Bruno Meloni,

University of Western

Australia, Australia

Arthur Schwartz,

Icahn School of Medicine at Mount

Sinai, United States

${ }^{*}$ Correspondence:

Neil J. Sprat

neil.spratt@health.nsw.gov.au

Specialty section:

This article was submitted to

Stroke,

a section of the journal

Frontiers in Neurology

Received: 23 March 2021

Accepted: 19 August 2021

Published: 20 September 2021

Citation:

Omileke D, Pepperall D, Bothwell SW,

Mackovski N, Azarpeykan S,

Beard DJ, Coupland K,

Patabendige A and Spratt NJ (2021) Ultra-Short Duration Hypothermia

Prevents Intracranial Pressure Elevation Following Ischaemic Stroke in Rats. Front. Neurol. 12:684353. doi: 10.3389/fneur.2021.684353

\section{Ultra-Short Duration Hypothermia Prevents Intracranial Pressure Elevation Following Ischaemic Stroke in Rats}

\author{
Daniel Omileke ${ }^{1,2}$, Debbie Pepperall ${ }^{1,2}$, Steven W. Bothwell ${ }^{1,2}$, Nikolce Mackovski ${ }^{1,2}$, \\ Sara Azarpeykan ${ }^{1,2}$, Daniel J. Beard ${ }^{1,2}$, Kirsten Coupland ${ }^{1,2}$, Adjanie Patabendige ${ }^{1,2}$ and \\ Neil J. Spratt ${ }^{1,2,3 *}$ \\ ${ }^{1}$ The School of Biomedical Sciences and Pharmacy, University of Newcastle, Callaghan, NSW, Australia, ${ }^{2}$ Hunter Medical \\ Research Institute, New Lambton, NSW, Australia, ${ }^{3}$ Department of Neurology, John Hunter Hospital, Hunter New England \\ Local Health District, New Lambton, NSW, Australia
}

There is a transient increase in intracranial pressure (ICP) $18-24 \mathrm{~h}$ after ischaemic stroke in rats, which is prevented by short-duration hypothermia using rapid cooling methods. Clinical trials of long-duration hypothermia have been limited by feasibility and associated complications, which may be avoided by short-duration cooling. Animal studies have cooled faster than is achievable in patients. We aimed to determine whether gradual cooling at a rate of $2^{\circ} \mathrm{C} / \mathrm{h}$ to $33^{\circ} \mathrm{C}$ or $1^{\circ} \mathrm{C} / \mathrm{h}$ to $34.5^{\circ} \mathrm{C}$, with a 30 min duration at target temperatures, prevented ICP elevation and reduced infarct volume in rats. Transient middle cerebral artery occlusion was performed, followed by gradual cooling to target temperature. Hypothermia to $33^{\circ} \mathrm{C}$ prevented significant ICP elevation (hypothermia $\Delta \mathrm{ICP}=1.56 \pm 2.26 \mathrm{mmHg}$ vs normothermia $\Delta \mathrm{ICP}=8.93 \pm 4.82 \mathrm{mmHg} ; p=0.02)$ and reduced infarct volume (hypothermia $=46.4 \pm 12.3 \mathrm{~mm}^{3}$ vs normothermia $=85.0 \pm$ $17.5 \mathrm{~mm}^{3} ; p=0.01$ ). Hypothermia to $34.5^{\circ} \mathrm{C}$ did not significantly prevent ICP elevation or reduce infarct volume. We showed that gradual cooling to $33^{\circ} \mathrm{C}$, at cooling rates achievable in patients, had the same ICP preventative effect as traditional rapid cooling methods. This suggests that this paradigm could be translated to prevent delayed ICP rise in stroke patients.

Keywords: intracranial pressure, hypothermia, middle cerebral artery occlusion, clinical translation, animal model

\section{INTRODUCTION}

Stroke is the second leading cause of death worldwide and the number one cause of permanent disability in adults $(1,2)$. A good collateral flow network is associated with better neurological outcome after stroke $(3,4)$. The collateral circulation provides residual perfusion to the "at-risk" penumbral tissue and slows down the progression of the infarct core.

Dramatic elevations in intracranial pressure (ICP) occur after experimental ischaemic stroke in animals - in young and aged rats, as well as rats of different strains (5-7). Our preliminary data indicates a significant ICP rise also occurs in stroke patients at $24 \mathrm{~h}(8)$. This ICP rise is a potential mechanism for collateral failure associated with delayed infarct expansion, worsening 
stroke outcome in patients $(9,10)$. We have previously shown that an increase in ICP causes a dramatic decrease in collateral blood flow and may therefore be responsible for collateral failure (9). Experimental studies have shown that ICP elevation occurs even after small strokes $(5,6,11,12)$ which may explain why it has gone unnoticed in patients with minor stroke, as ICP is normally only measured in large hemispheric stroke, due to the invasive nature of the procedure (13). Short-duration therapeutic hypothermia is a potent, easily implemented strategy that we have recently shown to have robust efficacy in preventing ICP elevation $24 \mathrm{~h}$ after stroke in rats (5-7). Multiple previous studies have shown that hypothermia also reduces infarct volume and improves functional outcome after experimental stroke (14), although at the time of these studies the effect on ICP was unknown, and the presumed mechanism of neuroprotection was by modification of a wide range of cell death mechanisms $(14,15)$. The effects of hypothermia on ICP elevation therefore suggests that direct effects on tissue perfusion via collateral vessels may be an important mechanism of hypothermic cytoprotection. Several early-phase clinical stroke trials using hypothermia as a treatment measure have shown feasibility. However, there is a significant mismatch in cooling duration used in clinical studies, from that shown to be effective in many experimental studies (16). Clinical trials of hypothermia have an average cooling duration of $24 \mathrm{~h}$, with many maintaining hypothermia for up to $72 \mathrm{~h}$ (15). In contrast, the vast majority of experimental studies have cooled for 1-6h (14). Additionally, rodent studies typically achieve target temperature within 10-20 min (14), a rate that cannot be achieved when cooling a human. The necessity of longduration hypothermia to achieve therapeutic outcome in stroke is questionable. Current protocols resulted from very early clinical studies in patients with extremely large, "malignant" middle cerebral artery (MCA) infarcts, in whom rebound ICP elevation during rewarming was extremely problematic, and on occasion fatal (17). However, these durations are logistically extremely challenging, and increase the risk of complications such as pneumonia (18). Moreover, our experimental data suggests short-duration cooling may prevent rebound ICP elevation, thus obviating the need for very prolonged rewarming. The mismatch between protocols shown to be effective in experimental studies, and those tested in clinical trials, needs to be addressed if there is any hope of translating therapeutic hypothermia for stroke treatment.

We hypothesized that a clinically achievable gradual cooling protocol may require even less time at target temperature than current methods to prevent ICP elevation post-stroke. A milder target temperature for a short duration is easier to achieve and would potentially increase feasibility. We previously showed that hypothermia to $35^{\circ} \mathrm{C}$ did not lead to a significant increase in ICP $24 \mathrm{~h}$ after stroke. However, a slight ICP rise was seen, suggesting that $35^{\circ} \mathrm{C}$ may be close to the threshold for hypothermia ICP rise prevention (6).

We aimed to determine the benefits of ultra-short duration hypothermia at target temperature on both ICP elevation and infarct volume reduction post-stroke. For this, two hypothermia target temperatures $\left(33\right.$ and $34.5^{\circ} \mathrm{C}$ ) were investigated to identify the most feasible hypothermia regimen that still effectively prevented ICP elevation. The "ultra-short" duration refers to the $30 \mathrm{~min}$ at target temperatures, which is far shorter than previous studies of short duration cooling (14). We chose $34.5^{\circ} \mathrm{C}$, slightly lower than the mildest effective target of $35^{\circ} \mathrm{C}$ from our previous work, to allow for our use of a gradual paradigm with less time at target temperature than in the previous study. ICP was measured epidurally using a fiber-optic catheter system. Epidural measurements were preferred in this study due to the increased risk of brain damage associated with other methods of ICP monitoring (19). Any damage to the brain has the potential to alter ICP, and therefore influence the primary outcome of this study. Moreover, previous studies have found that epidural ICP recordings correlate well with intraventricular recordings $(20,21)$, which are the "gold standard" of ICP measurements in humans (19). Additionally, the use of a fiber-optic probe provides high fidelity ICP signals when inserted and sealed in the epidural space $(19,22)$.

\section{MATERIALS AND METHODS \\ Animals and Experimental Protocol}

Adult male (11-12 weeks old) outbred Wistar rats $(n=23$, Animal Services Unit, University of Newcastle) weighing 280$320 \mathrm{~g}$ were used for this study. Animals were housed under standard conditions in a $12 \mathrm{~h}$ light-dark cycle with unlimited access to food and water. All experimental procedures were in accordance with the Australian Code of Practice for the Care and Use of Animals for Scientific Purposes and were approved by the Animal Care and Ethics Committee of the University of Newcastle (A-2013-343). This study was reported in accordance with the ARRIVE guidelines (23).

Rats were initially anesthetised in 5\% isoflurane in 50:50 $\mathrm{N}_{2}: \mathrm{O}_{2}$ in an induction chamber. Anesthesia was maintained with $2-2.5 \%$ isoflurane in the same gas mix and delivered via a custom, low dead space face mask with cross flow of gases. Incision sites were shaved, cleaned and injected subcutaneously (s.c.) with $2 \mathrm{mg} / \mathrm{kg}$ 0.05\% Bupivacaine (Pfizer, Sydney, Australia). Body temperature was regulated throughout the surgery with a rectal temperature thermocouple (RET-2, Physitemp Instruments Inc, Clifton, New Jersey, USA). The femoral artery was cannulated with a catheter consisting of 1 and 2 French silicone tubing for continuous monitoring of arterial blood pressure and heart rate and for measurement of arterial blood gases (i-STAT, Abbot, New Jersey, USA). Animals were randomized by sealed envelope to hypothermia treatment $\left(33\right.$ or $34.5^{\circ} \mathrm{C}$ ), or normothermia. After hypothermia treatment/ normothermia, rectal paracetamol (250 $\mathrm{mg} / \mathrm{kg}$, GlaxoSmithKline, Brentford, UK) was administered for recovery and overnight pain relief. Animals were also injected with saline $(2 \times 1.5 \mathrm{~mL}$, s.c. $)$ to prevent dehydration and were returned to their cages with free access to softened laboratory chow and water.

\section{Implantation of Datalogger Device}

A $2 \mathrm{~cm}$ longitudinal incision was made along the right abdominal region, proximal to the right thigh. The incision was made deep enough to expose the space at the ventral thigh crease. Haemostats and forceps were used to create a pocket under the 


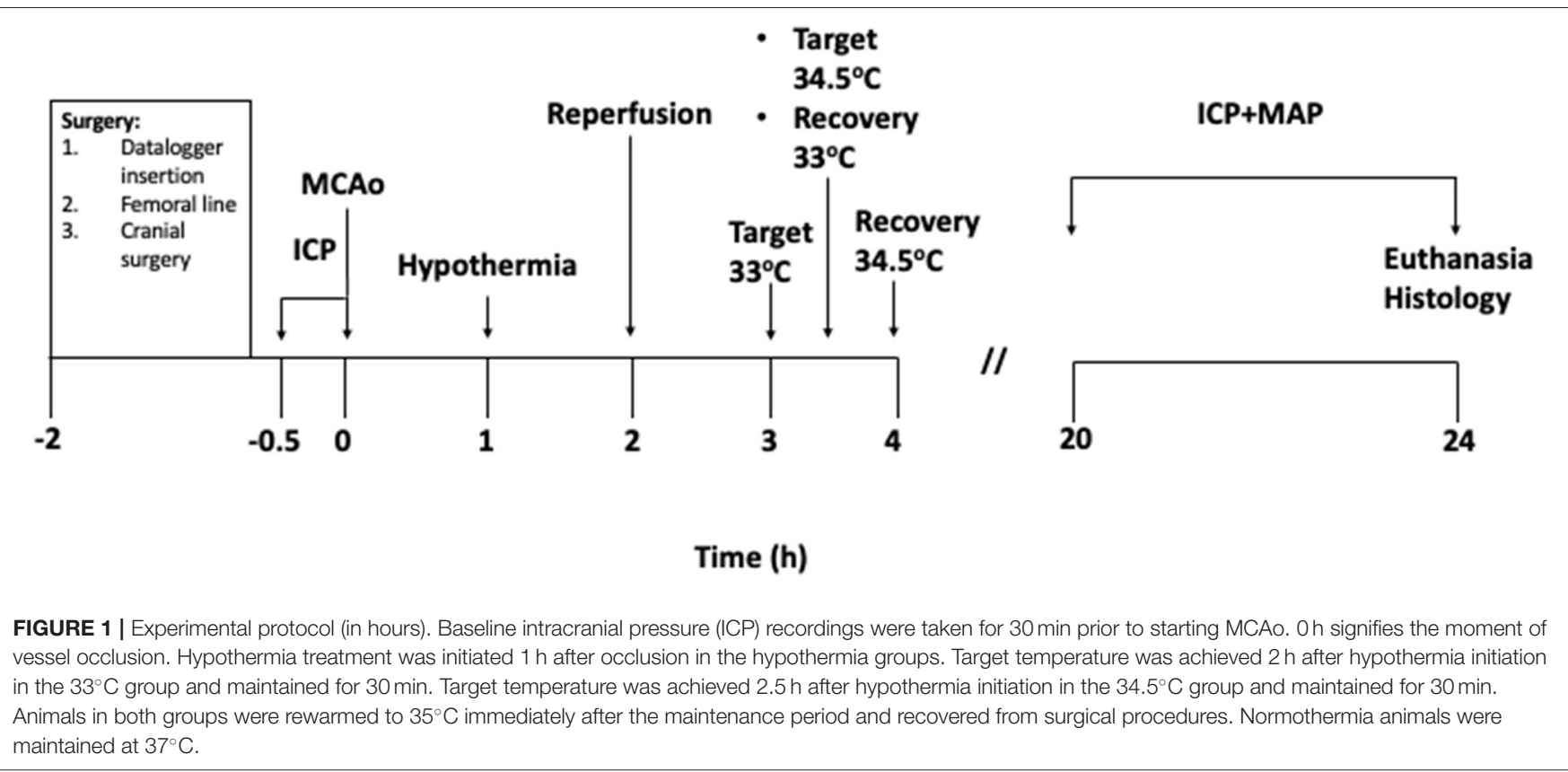

skin that was large enough to hold the device. The temperature monitoring datalogger (Maxim, San Jose, USA) was inserted into the pocket and secured by closing the muscle and skin with 5-0 silk sutures. Core body temperature was chosen as the desired temperature measurement location because it is minimally invasive and allows for post-operative and overnight monitoring. Additionally, we have previously compared core, rectal and brain temperature in rats and found that these temperatures track together during hypothermia induction, maintenance and rewarming (unpublished observations).

\section{Intracranial Pressure and Laser Doppler Measurement}

Cranial surgery was performed according to previously described methods (22). To summarize, the ICP probe (OpSens Fiber Optic Pressure Sensors, Canada) was inserted epidurally into a saline filled, polyether ether ketone (PEEK) screw (Bregma $2 \mathrm{~mm}$ posterior and $2 \mathrm{~mm}$ lateral) in the left parietal bone. Tissue perfusion in the territory supplied by the right middle cerebral artery was monitored during middle cerebral artery occlusion (MCAo) and reperfusion using laser Doppler flowmetry (LDF). The LDF probe (Moor Instruments, UK) was inserted into a second hollow PEEK screw (Bregma $2 \mathrm{~mm}$ posterior and $5 \mathrm{~mm}$ lateral) in the right parietal bone. For ICP and LDF recordings, the screws were secured with dental cement and an airtight seal was created around each probe using a caulking material (Silagum, Gunz Dental, Germany). Correct placement of the ICP probe was confirmed by a response to abdominal compression which was observed on both ICP and arterial blood pressure waveforms. ICP was monitored at pre-stroke baseline and again at 20-24 h post-stroke (Figure 1). Cerebral perfusion pressure (CPP) is the difference between mean arterial pressure and ICP, and was therefore calculated by subtracting these two values. To account for minor variations between the baseline ICP and CPP of the 3 experimental groups, change in ICP from baseline to $24 \mathrm{~h}$ $(\triangle \mathrm{ICP})$, and change in CPP from baseline to $24 \mathrm{~h}(\triangle \mathrm{CPP})$ were used for all ICP and CPP analyses.

\section{Middle Cerebral Artery Occlusion}

Transient middle cerebral artery occlusion (MCAo) was carried out according to our established protocol $(24,25)$. To summarize, a $6 \mathrm{~cm}$ length of monofilament nylon suture $(3 \mathrm{~mm}$ length $\times 0.38 \mathrm{~mm}$ O.D silicone) was inserted into the ligated right external carotid artery. The filament was advanced $20 \mathrm{~mm}$ through the internal carotid artery, avoiding the pterygopalatine artery, until resistance was felt, and a drop in perfusion units ( $>50 \%$ drop from baseline) on the LDF was observed which indicated that the middle cerebral artery has been occluded. At $2 \mathrm{~h}$ post-occlusion, reperfusion was achieved by retracting the monofilament through the internal carotid artery approximately $18 \mathrm{~mm}$ until the silicone tip was visible in the external carotid artery stump.

\section{Hypothermia Treatment}

After $1 \mathrm{~h}$ of MCAo, hypothermia-treated animals were cooled gradually by reducing the temperature of the heat mat in small increments (26) to a target core temperature of 33 or $34.5^{\circ} \mathrm{C}$. Animals were cooled to target over $2 \mathrm{~h}$ in the $33^{\circ} \mathrm{C}$ group (rate $2^{\circ} \mathrm{C} / \mathrm{h}$ ) and over $2.5 \mathrm{~h}$ in the $34.5^{\circ} \mathrm{C}$ group (rate $1^{\circ} \mathrm{C} / \mathrm{h}$ ), and maintained at target for $30 \mathrm{~min}$. This gave an overall cooling duration of $2.5 \mathrm{~h}$ and $3 \mathrm{~h}$, respectively. No external cooling was necessary as anesthesia prevents normal regulation of core body temperature (Figure 2). For recovery and rewarming, core body temperature was increased to $35^{\circ} \mathrm{C}$ by adjusting the heat mat. Animals were placed in a cage half over a warming pad (Passwell, South Australia) to allow for thermoregulation 


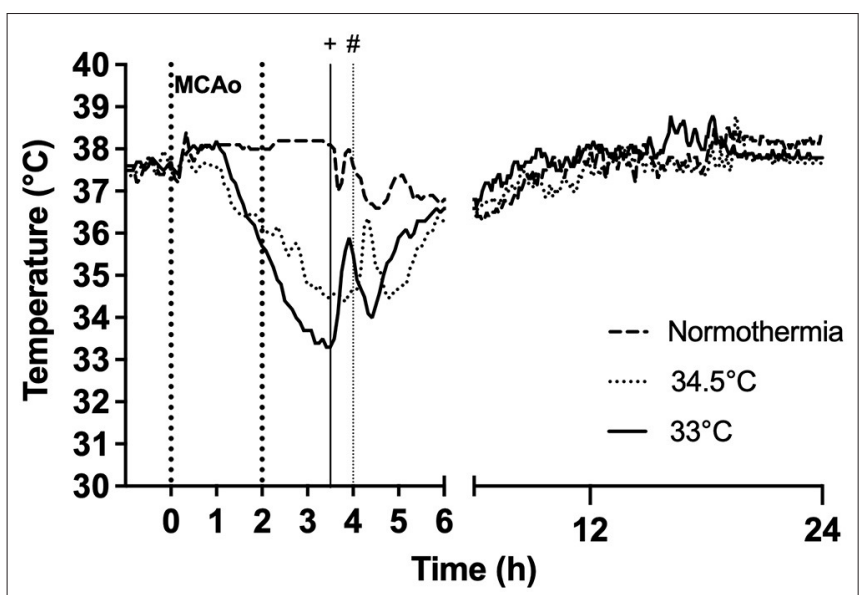

FIGURE 2 | Effect of gradual cooling protocol on core body temperature (datalogger) in rats subjected to hypothermia at $33^{\circ} \mathrm{C}$ and $34.5^{\circ} \mathrm{C}$. Vertical dotted lines at $\mathrm{Oh}$ to $2 \mathrm{~h}$ refer to duration of occlusion. Hypothermia was initiated at $1 \mathrm{~h}$ post-occlusion in both $33^{\circ} \mathrm{C}$ and $34.5^{\circ} \mathrm{C}$ groups. Target temperature was reached at $3 \mathrm{~h}$ post-occlusion in the $33^{\circ} \mathrm{C}$ group and $3.5 \mathrm{~h}$ post-occlusion in the $34.5^{\circ} \mathrm{C}$ group. "+" indicates rewarming was initiated at $3.5 \mathrm{~h}$ in the $33^{\circ} \mathrm{C}$ group and "\#" indicates rewarming initiation at $4 \mathrm{~h}$ in the $34.5^{\circ} \mathrm{C}$ group.

back to normothermia. Animals in the $33^{\circ} \mathrm{C}$ took $127 \pm$ $36.4 \mathrm{~min}$ to thermoregulate back to normothermia. Animals in the $34.5^{\circ} \mathrm{C}$ group took $116 \pm 39.4 \mathrm{~min}$ to thermoregulate back to normothermia. Animals in the normothermia group were maintained at $37^{\circ} \mathrm{C}$ for the duration of the surgery.

\section{Histological Analysis and Infarct Volume Measurement}

Animals were euthanised $24 \mathrm{~h}$ post-stroke onset. They were transcardially perfused with saline and their brains were removed and sectioned into 6 coronal slices using a rat brain matrix, each of $2 \mathrm{~mm}$ thickness.

Triphenyltetrazolium chloride (TTC) (Sigma-Aldrich, Missouri, USA) staining was performed to confirm the presence of ischaemic stroke by identification of infarcted tissue. The slices from each brain were incubated for $12 \mathrm{~min}$ at $37^{\circ} \mathrm{C}$ in $2 \%$ TTC. TTC was used for early confirmation of infarct, however, haematoxylin and eosin (H\&E) staining was then used on the same tissue for infarct volume quantification. Infarct volume quantification was carried out using our routine procedure (27). Tissues were fixed, processed, paraffin embedded and cut at $10 \mu \mathrm{m}$ coronal sections. Images were scanned using a high-resolution scanner (Aperio, Vista, CA, USA) and analyzed by an investigator blinded to treatment allocation. Infarct (corrected for oedema) was calculated (Aperio ImageScope) by subtracting the measured interhemispheric volume difference from the measured infarct volume for each side. Infarct volumes were corrected for oedema by applying the formula: corrected infarct volume $\left(\mathrm{mm}^{3}\right)=$ infarct volume $\times$ (contralateral volume/ipsilateral volume). Oedema was calculated by infarct volume minus corrected infarct volume (6).

\section{Exclusion Criteria and Statistical Analysis}

Subarachnoid hemorrhage (SAH), equipment malfunction and lack of $>50 \%$ LDF drop at occlusion were pre-specified exclusion criteria.

A sample size calculation was performed using pilot and previous data $(5,6)\left(G^{*}\right.$ Power version 3.1$)$ which indicated that 4 animals per group were required to detect a $10 \mathrm{mmHg}$ difference in $\triangle \mathrm{ICP}$ between the hypothermia and normothermia groups $(\triangle \mathrm{ICP}=$ mean peak ICP - mean baseline ICP $)$ with standard settings of alpha 0.05 , power 0.8 . A sample size of 5 animals per group was decided upon to allow for any outlier effects. Statistical analyses were performed using GraphPad Prism version 8.2.1. Data were tested for normal distribution using the ShapiroWilk normality test. One-way analyses of variance (ANOVA) were used to compare differences between the treatment groups (main effect) followed by Tukey's post-hoc test for multiple comparisons between groups when a significant difference was found. Student's $t$-test (paired) were performed to compare changes from baseline. Statistical significance was accepted at $p<$ 0.05 . Data are presented as mean $\pm \mathrm{SD}$ unless otherwise stated.

\section{RESULTS}

A total of 15 animals were included in this study: 5 treated with hypothermia to $33^{\circ} \mathrm{C}, 5$ treated with hypothermia to $34.5^{\circ} \mathrm{C}$ and 5 normothermia controls. A total of 8 animals were excluded. Reasons for exclusion were lack of sufficient LDF drop $(n=5)$, SAH detected post-mortem $(n=1)$ and unexpected death from surgical complications $(n=2)$.

\section{Gradual Cooling Slowly Reduces Body Temperature}

Both cooling protocols achieved a gradual decrease of core body temperature to target (Figure 2). Core temperatures during the 30 min at target were $33.2 \pm 0.27^{\circ} \mathrm{C}$ and $34.5 \pm 0.22^{\circ} \mathrm{C}$ in the two hypothermia groups. Normothermia animals were maintained at normal core body temperature for the duration of this period. In the hypothermia groups, animals reached target at $117.8 \pm$ $26.9 \mathrm{~min}$ in the $33^{\circ} \mathrm{C}$ group and $152.2 \pm 2.3 \mathrm{~min}$ in the $34.5^{\circ} \mathrm{C}$ group. Physiological parameters are presented in Table $\mathbf{1 .}$

\section{Gradual Cooling to $33^{\circ} \mathrm{C}$ Prevents ICP Elevation $24 \mathrm{~h}$ Post-Stroke}

ICP rose significantly from baseline to $24 \mathrm{~h}$ in the normothermia group $(\triangle \mathrm{ICP}=8.93 \pm 4.82 \mathrm{mmHg}$ : Figure $3 \mathrm{~A})$. There was a significant main effect between treatment groups, $\mathrm{F}(2,12)$ $=5.1, p=0.02$. Tukey post-hoc test showed that there was significantly less ICP elevation in the $33^{\circ} \mathrm{C}$ group compared to normothermia, $(\Delta \mathrm{ICP}=1.56 \pm 2.26 \mathrm{mmHg} ; p=0.02)$. ICP increased slightly in the $34.5^{\circ} \mathrm{C}$ group which resulted in a nonsignificant difference when compared to normothermia $(\triangle \mathrm{ICP}$ $=5.32 \pm 3.34 \mathrm{mmHg} ; p=0.29$ ). CPP decreased significantly from baseline to $24 \mathrm{~h}$ in the normothermia group $(\triangle \mathrm{CPP}=$ $-10.21 \pm 3.62 \mathrm{mmHg}$ : Figure 3B). There was a significant main effect between treatment groups, $\mathrm{F}(2,12)=5.461, p=0.02$. Hypothermia animals in the $33^{\circ} \mathrm{C}$ group showed an increase in 
TABLE 1 | Physiological parameters.

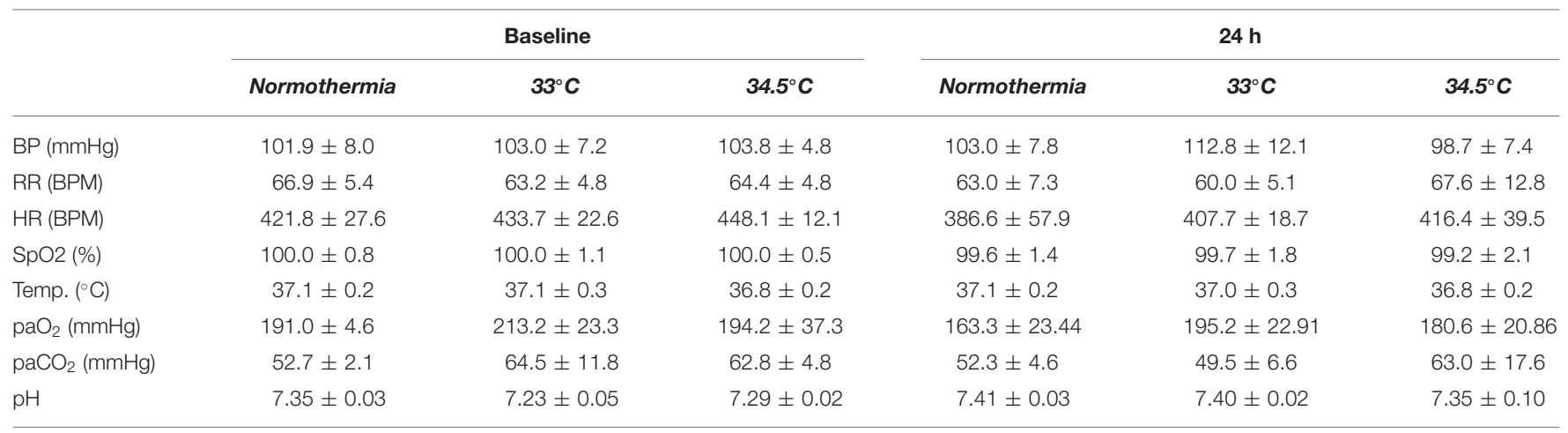

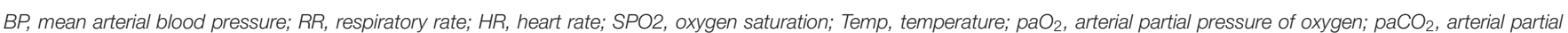
pressure of carbon dioxide. Presented for illustrative purposes only.

CPP from baseline to $24 \mathrm{~h}$ when compared to normothermia $(\triangle \mathrm{CPP}=6.35 \pm 9.33 \mathrm{mmHg}, p=0.04)$. Hypothermia animals in the $34.5^{\circ} \mathrm{C}$ group showed no difference in CPP when compared with normothermia ( $\triangle \mathrm{CPP}=-11.93 \pm 13.41 \mathrm{mmHg}, p=0.96)$.

\section{Gradual Cooling to $33^{\circ} \mathrm{C}$ Reduced Infarct Volume 24 h Post-Stroke}

There was a significant main effect between treatment groups, $\mathrm{F}(2,12)=8.338, p=0.005$ - (Figure 4). Hypothermia treated animals to $33^{\circ} \mathrm{C}$ had significantly smaller infarct volumes than normothermia controls $\left(46.4 \pm 12.3 \mathrm{~mm}^{3}\right.$ and $85.0 \pm 17.5$ $\mathrm{mm}^{3}$, respectively, $\left.p=0.01\right)$. Hypothermia treated animals to $34.5^{\circ} \mathrm{C}$ did not have smaller infarct volumes when compared to normothermia controls $\left(87.2 \pm 22.1 \mathrm{~mm}^{3} p=0.98\right)$. Representative images are also presented in Figure 4.

\section{DISCUSSION}

In this study, we have shown that clinically achievable gradual cooling to $33^{\circ} \mathrm{C}$, with only $30 \mathrm{~min}$ at target temperature, prevented significant elevation of ICP and reduced infarct volume $24 \mathrm{~h}$ post-stroke. We have previously shown that $2.5 \mathrm{~h}$ hypothermia to $32.5^{\circ} \mathrm{C}$ prevented ICP rise at $24 \mathrm{~h}$ in both young adult and aged rats, and in different strains $(6,7)$. In these previous studies, a target temperature of $32.5^{\circ} \mathrm{C}$ was achieved within $20 \mathrm{~min}$ and rats were maintained at target for $130 \mathrm{~min}$ (the remainder of the $2.5 \mathrm{~h}$ duration) before being rewarmed. This current study suggests that hypothermia has the same ICP rise prevention properties as previously shown (5-7), even when using a clinically achievable cooling rate with a shorter duration at target temperature.

The results of this study support previous work indicating a likely link between ICP rise prevention and neuroprotection, resulting from hypothermia. Following an ischaemic stroke, the penumbra is kept temporarily viable by perfusion from the collateral vessels. The blood flow to the ischaemic penumbra is known to be dependent on CPP: the difference between mean arterial pressure and ICP. ICP elevation after stroke causes a reduction in $\mathrm{CPP}$, which thereby reduces blood flow to the penumbra and may be responsible for infarct expansion $(6,9)$.
Preliminary data on human stroke patients also demonstrate an ICP rise $24 \mathrm{~h}$ post-stroke (8). At the same time, we have shown that a short period of moderate hypothermia in rats prevents ICP rise, even in the presence of large strokes (7). Previous studies have also shown that hypothermia-treated animals with no ICP elevation also tend to have smaller infarct volumes at $24 \mathrm{~h}$ than their normothermia counterparts $(5,6)$.

In this present study, we have shown that hypothermia to $34.5^{\circ} \mathrm{C}$ did not significantly prevent ICP elevation or reduce infarct volume. These results have important implications because it suggests that a longer duration at target temperature might be necessary for milder hypothermia $\left(\geq 34.5^{\circ} \mathrm{C}\right)$. Previous animal studies have shown that hypothermia to target temperatures as mild as $35^{\circ} \mathrm{C}$ for $2 \mathrm{~h}$ reduces infarct volume (14). However, there does appear to be a depth-response relationship in which lower temperatures provide greater benefit $(28,29)$. The lack of efficacy seen in the $34.5^{\circ} \mathrm{C}$ group in this study is likely due to the ultra-short duration for which target temperature was maintained. This finding suggests that, for a much slower cooling rate, either a greater temperature depth or a longer duration at target temperature is likely required to show benefit. However, at a target temperature of $33^{\circ} \mathrm{C}$ we found that a short duration of $30 \mathrm{~min}$ had similar protective effects on ICP elevation and infarct volume to those shown in studies where target temperature is maintained for longer periods (5-7).

While there are some data suggesting that longer durations of cooling may be required for neuroprotection when the onset of hypothermia is delayed $(30,31)$, it is evident from experimental studies that a prolonged period of treatment is not necessary when hypothermia is initiated shortly after vessel occlusion and during reperfusion. However, additional studies will be required to determine how long the interval from stroke onset to treatment can be, while still maintaining effectiveness. Previous studies by our group (5-7) and this present study have initiated hypothermia $1 \mathrm{~h}$ after vessel occlusion and have demonstrated ICP rise prevention at $24 \mathrm{~h}$. The fact that we were still able to see such robust effects with a very short duration at target temperature suggests that perhaps the most important parameter is reaching target temperature and not necessarily the amount of time spent at target. While a $30 \mathrm{~min}$ 

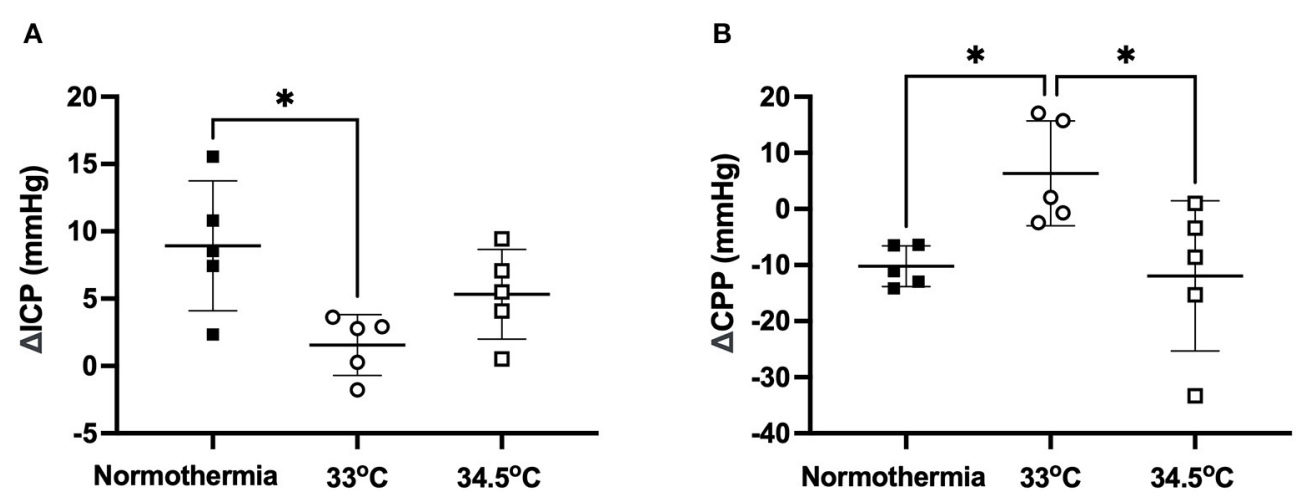

FIGURE 3 | (A) Change in ICP from baseline to $24 \mathrm{~h}$ in the $33^{\circ} \mathrm{C}$ and $34.5^{\circ} \mathrm{C}$ hypothermia groups and normothermia control. (B) Change in CPP from baseline to $24 \mathrm{~h}$ in the $33^{\circ} \mathrm{C}$ and $34.5^{\circ} \mathrm{C}$ hypothermia groups and normothermia control. ${ }^{*}$ denotes statistical significance where $p<0.05$.

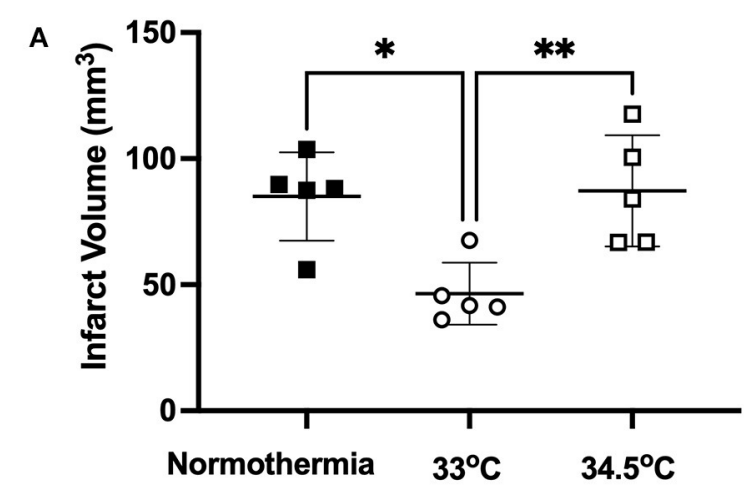

B

1

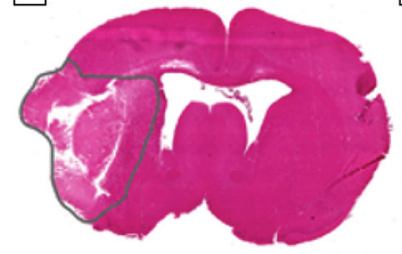

2

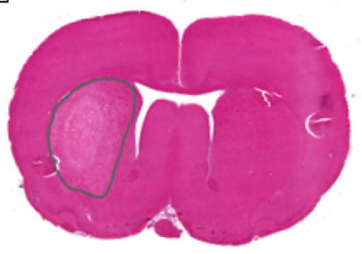

3

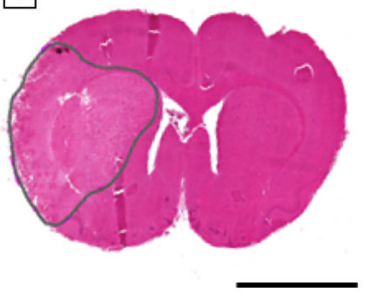

FIGURE 4 | (A) Infarct volume from H\&E staining at $24 \mathrm{~h}$ measured in all groups. * denotes statistical significance where $p<0.05$, ${ }^{\star \star}$ denotes statistical significance where $p<0.01$. (B) Representative H\&E images of infarct size of (1) normothermia controls, (2) hypothermia $33^{\circ} \mathrm{C}$ and $(3)$ hypothermia $34.5^{\circ} \mathrm{C}$ animals at $24 \mathrm{~h}$ post-stroke. Dotted gray lines indicate region of infarct. Scale bar $=4 \mathrm{~mm}$.

duration at $33^{\circ} \mathrm{C}$ was used in this study, it is possible that we may have achieved the same results had we cooled to target temperature and immediately rewarmed. This short-duration approach could make hypothermia much more clinically feasible, as the therapy can be initiated at the time of sedation for endovascular thrombectomy, for example.

Our results have demonstrated that clinically relevant cooling rates are feasible and effective in rats. The rate of cooling is an important factor from a translational standpoint and is often not the focus in experimental stroke studies utilizing hypothermia. It has been well documented that humans take considerably longer to cool to target temperature than rodents because of differences in surface area to volume ratio (26). Target temperature is achieved very rapidly in animals; for example, previous work from our group has shown that a target temperature of $32.5^{\circ} \mathrm{C}$ can be achieved within $20 \mathrm{~min}$ (5). This gives us a rate of 
$0.23^{\circ} \mathrm{C} / \mathrm{min}$ or $13.8^{\circ} \mathrm{C} / \mathrm{h}$. This is clearly not comparable to human cooling rates, for example the endovascular cooling feasibility study by Georgiadis et al. found that the cooling rate for stroke patients to reach a target temperature of $33^{\circ} \mathrm{C}$ was $1.4 \pm 0.6^{\circ} \mathrm{C} / \mathrm{h}$ (32). The gradual cooling model used in this present study is a major improvement for animal studies with a cooling rate of $2^{\circ} \mathrm{C} / \mathrm{h}$ in the $33^{\circ} \mathrm{C}$ group and $1^{\circ} \mathrm{C} / \mathrm{h}$ in the $34.5^{\circ} \mathrm{C}$ group.

We have demonstrated, using a novel method of gradual hypothermia coupled with intensive temperature monitoring, that cooling rates shown to be achieved in humans, can also be achieved in rats. A limitation of this study was that we did not use the same endovascular cooling method that is common in human hypothermia trials. However, there are currently no methods available in small animals that precisely mimic endovascular cooling in humans. Another limitation of this study is that we did not explore whether the robust neuroprotection of hypothermia extends beyond the $24 \mathrm{~h}$ observational window. However, the $24 \mathrm{~h}$ timepoint is important because it is when ICP elevation peaks post-stroke (5-7). Investigations into the long-term efficacy of hypothermia beyond $24 \mathrm{~h}$ will be the focus of future studies. Additionally, further studies will be required to explore the efficacy of short-duration cooling to $34.5^{\circ} \mathrm{C}$. This milder temperature may have more robust effects on ICP elevation and infarct volume than was shown in this study if for example, a longer duration at target temperature was used. Neurological deficit assessments were not included in this study. While it is important to determine whether the neuroprotection offered by hypothermia to $33^{\circ} \mathrm{C}$ extends to neurological deficits, we were powered based on our primary outcome of $\triangle \mathrm{ICP}$, not neurological deficit scores. Sample size calculations for neurological scores or other behavioral measures would result in much larger group sizes (33).

Lastly, there was a brief occurrence of post-operative hypothermia in all groups in which core body temperature dropped for a short period after rewarming. However, postoperative hypothermia is a universal phenomenon that occurs (34) but is often not measured. While every effort was made to ensure adequate rewarming in the hypothermia groups, the fact that we also saw this dip in temperature occur in our normothermia controls suggest that it is not a factor that influenced the results obtained.

In conclusion, long durations of cooling and their resulting complications have limited large-scale clinical trials and would likely limit the application of long-duration hypothermia as a widely used therapy in stroke. Achieving target temperature has been a challenge in clinical trials of hypothermia in stroke; however, this step may be critical to patient outcome. The lack of benefit seen at $34.5^{\circ} \mathrm{C}$ highlights the critical importance of achieving target temperature. Recent results from one of the most prominent early-phase clinical trials of hypothermia for ischaemic stroke (EuroHYP-1) found that only 31\% of patients recruited achieved target temperature $\left(34-35^{\circ} \mathrm{C}\right)$ and suggest this as a potential reason for the lack of benefit reported in the study (35). There is only a $1.5^{\circ} \mathrm{C}$ difference in target temperature between the two treatments groups in the present study, yet we have shown a dramatic difference in outcome between the groups. This narrow window of effect may also be present in humans, therefore ensuring that target temperature is achieved may have significant impacts on patient outcome. Moreover, the effectiveness of only $30 \mathrm{~min}$ at $33^{\circ} \mathrm{C}$ highlights the fact that much shorter durations of cooling than those used in clinical trials may be effective with early treatment initiation. In recent years, methods have been well established to achieve rapid cooling in patients using whole-body techniques such as endovascular or skin cooling (15). Direct brain cooling strategies such as intranasal (36) and intracarotid cooling (37) are less well established but are under investigation.

Our results suggest that a very short time period at $33^{\circ} \mathrm{C}$ may be all that is necessary to prevent significant ICP elevation and reduce infarct volume if cooling is initiated early. Further definition of the time window for treatment initiation will be needed, however, these results raise the prospect of benefit from a far more feasible hypothermia paradigm that has previously been tested, and hope that the long-recognized neuroprotective benefits may be able to be realized for stroke patients.

\section{DATA AVAILABILITY STATEMENT}

The raw data supporting the conclusions of this article will be made available by the authors, without undue reservation.

\section{ETHICS STATEMENT}

The animal study was reviewed and approved by the Animal Care and Ethics Committee of the University of Newcastle.

\section{AUTHOR CONTRIBUTIONS}

DO performed the experimental study, analysed and interpreted the data, performed the statistical analyses and drafted the manuscript. NM and SA contributed to the experimental part of the study. DP and SWB were involved in the histological and image analysis for the study. DJB, KC, AP, and NJS conceived the study and participated in its design and coordination. All authors have read and approved the final manuscript.

\section{FUNDING}

DO was supported by an International Postgraduate Research Scholarship awarded by the University of Newcastle. DJB was supported by the National Health and Medical Research Council Australia (APP1182153). KC was supported by the Hunter Medical Research Institute under the Dalara Early Career Researcher Fellowship. AP was supported by the NSW Ministry of Health under the NSW Health Early-Mid Career Research Fellowship Scheme. NJS was supported by a cofunded Australian National Health and Medical Research Council/National Heart Foundation Career Development/Future Leader Fellowship [GNT1110629/100827]. 


\section{REFERENCES}

1. Di Carlo A. Human and economic burden of stroke. Age Ageing. (2009) 38:4-5. doi: 10.1093/ageing/afn282

2. Feigin VL, Krishnamurthi RV, Parmar P, Norrving B, Mensah GA, Bennett $\mathrm{DA}$, et al. Update on the global burden of ischemic and hemorrhagic stroke in 1990-2013: the GBD 2013 study. Neuroepidemiology. (2015) 45:16176. doi: 10.1159/000441085

3. Shuaib A, Butcher K, Mohammad AA, Saqqur M, Liebeskind DS. Collateral blood vessels in acute ischaemic stroke: a potential therapeutic target. Lancet Neurol. (2011) 10:909-21. doi: 10.1016/S1474-4422(11) 70195-8

4. Leng X, Fang H, Leung TW, Mao C, Miao Z, Liu L, et al. Impact of collaterals on the efficacy and safety of endovascular treatment in acute ischaemic stroke: a systematic review and meta-analysis. J Neurol Neurosurg Psychiatry. (2016) 87:537-44. doi: 10.1136/jnnp-2015-310965

5. Murtha LA, McLeod DD, McCann SK, Pepperall D, Chung S, Levi CR, et al. Short-duration hypothermia after ischemic stroke prevents delayed intracranial pressure rise. Int J Stroke. (2014) 9:553-9. doi: 10.1111/ijs. 12181

6. Murtha LA, McLeod DD, Pepperall D, McCann SK, Beard DJ, Tomkins AJ, et al. Intracranial pressure elevation after ischemic stroke in rats: cerebral edema is not the only cause, and short-duration mild hypothermia is a highly effective preventive therapy. J Cereb Blood Flow Metab. (2015) 35:592600. doi: 10.1038/jcbfm.2014.230

7. Murtha LA, Beard DJ, Bourke JT, Pepperall D, McLeod DD, Spratt NJ. Intracranial pressure elevation $24 \mathrm{~h}$ after ischemic stroke in aged rats is prevented by early, short hypothermia treatment. Front Aging Neurosci. (2016) 8:124. doi: 10.3389/fnagi.2016.00124

8. Kovacs T, Murtha L, Beard D, McLeod D, Hood R, Garcia-Esperon C, et al. A potential cause of early neurological deterioration after mild-moderate ischaemic stroke - raised intracranial pressure at 24 hours. Int J Stroke. (2017) 12:34-34.

9. Beard DJ, McLeod DD, Logan CL, Murtha LA, Imtiaz MS, van Helden $\mathrm{DF}$, et al. Intracranial pressure elevation reduces flow through collateral vessels and the penetrating arterioles they supply. A possible explanation for "collateral failure" and infarct expansion after ischemic stroke. J Cereb Blood Flow Metab. (2015) 35:861-72. doi: 10.1038/jcbfm. 2015.2

10. Campbell BC, Christensen S, Tress BM, Churilov L, Desmond PM, Parsons MW, et al. Failure of collateral blood flow is associated with infarct growth in ischemic stroke. J Cereb Blood Flow Metab. (2013) 33:116872. doi: $10.1038 /$ jcbfm.2013.77

11. Beard DJ, Logan CL, McLeod DD, Hood RJ, Pepperall D, Murtha LA, et al. Ischemic penumbra as a trigger for intracranial pressure rise - a potential cause for collateral failure and infarct progression? J Cereb Blood Flow Metab. (2016) 36:917-27. doi: 10.1177/0271678X15625578

12. Patabendige A, MacKovski N, Pepperall D, Hood R, Spratt N. Correction to: A26 cerebrospinal fluid outflow resistance is increased following small-moderate ischaemic stroke. Fluids Barriers CNS. (2019) 16:22. doi: 10.1186/s12987-019-0144-7

13. Raboel $\mathrm{PH}$, Bartek J, Andresen M, Bellander BM, Romner B. Intracranial pressure monitoring: invasive versus non-invasive methodsa review. Crit Care Res Pract. (2012) 2012:950393. doi: 10.1155/2012/9 50393

14. van der Worp HB, Sena ES, Donnan GA, Howells, DW, MacLeod MR. Hypothermia in animal models of acute ischaemic stroke: a systematic review and meta-analysis. Brain. (2007) 130:3063-74. doi: 10.1093/brain/ awm083

15. Wu TC, Grotta JC. Hypothermia for acute ischaemic stroke. Lancet Neurol. (2013) 12:275-84. doi: 10.1016/S1474-4422(13) 70013-9

16. van der Worp HB, Macleod MR, Bath PM, Demotes J, Durand-Zaleski I, Gebhardt B, et al. EuroHYP-1: European multicenter, randomized, phase III clinical trial of therapeutic hypothermia plus best medical treatment vs. best medical treatment alone for acute ischemic stroke. Int J Stroke. (2014) 9:642-5. doi: 10.1111/ijs.12294
17. Schwab S, Schwarz S, Spranger M, Keller E, Bertram M, Hacke W. Moderate hypothermia in the treatment of patients with severe middle cerebral artery infarction. Stroke. (1998) 29:2461-6. doi: 10.1161/01.STR.29. 12.2461

18. Lyden P, Ernstrom K, Raman R. Determinants of pneumonia risk during endovascular hypothermia. Ther Hypothermia Temp Manag. (2013) 3:247. doi: $10.1089 /$ ther.2012.0021

19. Zhong J, Dujovny M, Park HK, Perez E, Perlin AR, Diaz FG. Advances in ICP monitoring techniques. Neurol Res. (2003) 25:339-50. doi: 10.1179/0161641031012 01661

20. Uldall $M$, Juhler $M$, Skjolding AD, Kruuse C, Jansen-Olesen I, Jensen $\mathrm{R}$, et al. novel method for long-term monitoring of intracranial pressure in rats. J Neurosci Methods. (2014) 227:1-9. doi: 10.1016/j.jneumeth.2014. 01.036

21. Nornes H, Sundbarg G. Simultaneous recording of the ventricular fluid pressure and the epidural pressure. Eur Neurol. (1972) 7:36472. doi: $10.1159 / 000114440$

22. Murtha L, McLeod D, Spratt N. Epidural intracranial pressure measurement in rats using a fiber-optic pressure transducer. J Vis Exp. (2012) 62:3689. doi: 10.3791/3689

23. Percie du Sert N, Hurst V, Ahluwalia A, Alam S, Avey MT, Baker M, et al. The ARRIVE guidelines 2.0: updated guidelines for reporting animal research. J Cereb Blood Flow Metab. (2020) 40:1769-77. doi: 10.1177/0271678X209 43823

24. Spratt NJ, Fernandez J, Chen M, Rewell S, Cox S, van Raay L, et al. Modification of the method of thread manufacture improves stroke induction rate and reduces mortality after thread-occlusion of the middle cerebral artery in young or aged rats. J Neurosci Methods. (2006) 155:28590. doi: 10.1016/j.jneumeth.2006.01.020

25. McLeod DD, Beard DJ, Parsons MW, Levi CR, Calford MB, Spratt NJ. Inadvertent occlusion of the anterior choroidal artery explains infarct variability in the middle cerebral artery thread occlusion stroke model. PLoS ONE. (2013) 8:e75779. doi: 10.1371/journal.pone.0075779

26. Omileke D, Bothwell S, Beard DJ, Mackovski N, Azarpeykan S, Coupland K, et al. Short-duration hypothermia induction in rats using models for studies examining clinical relevance and mechanisms. J Vis Exp. (2021) 169:e62325. doi: $10.3791 / 62325$

27. McLeod DD, Parsons MW, Levi CR, Beautement S, Buxton D, Roworth B, et al. Establishing a rodent stroke perfusion computed tomography model. Int J Stroke. (2011) 6:284-9. doi: 10.1111/j.1747-4949.2010.00564.x

28. Kollmar R, Blank T, Han JL, Georgiadis D, Schwab S. Different degrees of hypothermia after experimental stroke: short- and long-term outcome. Stroke. (2007) 38:1585-9. doi: 10.1161/STROKEAHA.106.475897

29. Lyden PD, Lamb J, Kothari S, Toossi S, Boitano P, Rajput PS. Differential effects of hypothermia on neurovascular unit determine protective or toxic results: Toward optimized therapeutic hypothermia. J Cereb Blood Flow Metab. (2019) 9:1693-709. doi: 10.1177/0271678X18814614

30. Kurisu K, Yenari MA. Therapeutic hypothermia for ischemic stroke; pathophysiology and future promise. Neuropharmacology. (2018) 134:3029. doi: 10.1016/j.neuropharm.2017.08.025

31. Colbourne F, Li H, Buchan AM. Indefatigable CA1 sector neuroprotection with mild hypothermia induced 6 hours after severe forebrain ischemia in rats. J Cereb Blood Flow Metab. (1999) 19:742-9. doi: 10.1097/00004647-199907000-00003

32. Georgiadis D, Schwarz S, Kollmar R, Schwab S. Endovascular cooling for moderate hypothermia in patients with acute stroke: first results of a novel approach. Stroke. (2001) 32:2550-3. doi: 10.1161/hs1101.097382

33. Rewell SSJ, Churilov L, Sidon TK, Aleksoska E, Cox SF, Macleod MR, et al. Evolution of ischemic damage and behavioural deficit over 6 months after MCAo in the rat: selecting the optimal outcomes and statistical power for multi-centre preclinical trials. PLoS ONE. (2017) 12:e0171688. doi: 10.1371/journal.pone.0171688

34. Campbell K, Meloni BP, Zhu H, Knuckey NW. Magnesium treatment and spontaneous mild hypothermia after transient focal cerebral ischemia in the rat. Brain Res Bull. (2008) 77:320-2. doi: 10.1016/j.brainresbull.2008. 08.017 
35. van der Worp HB, Macleod MR, Bath PM, Bathula R, Christensen H, Colam $\mathrm{B}$, et al. Therapeutic hypothermia for acute ischaemic stroke. Results of a European multicentre, randomised, phase III clinical trial. Eur Stroke J. (2019) 4:254-62. doi: 10.1177/2396987319844690

36. Abou-Chebl A, Sung G, Barbut D, Torbey M. Local brain temperature reduction through intranasal cooling with the RhinoChill device: preliminary safety data in brain-injured patients. Stroke. (2011) 42:2164-9. doi: 10.1161/STROKEAHA.110.613000

37. Cattaneo G, Meckel S. Review of selective brain hypothermia in acute ischemic stroke therapy using an intracarotid, closed-loop cooling catheter. Brain Circ. (2019) 5:211-7. doi: 10.4103/bc.bc_54_19

Conflict of Interest: The authors declare that the research was conducted in the absence of any commercial or financial relationships that could be construed as a potential conflict of interest.
Publisher's Note: All claims expressed in this article are solely those of the authors and do not necessarily represent those of their affiliated organizations, or those of the publisher, the editors and the reviewers. Any product that may be evaluated in this article, or claim that may be made by its manufacturer, is not guaranteed or endorsed by the publisher.

Copyright (C) 2021 Omileke, Pepperall, Bothwell, Mackovski, Azarpeykan, Beard, Coupland, Patabendige and Spratt. This is an open-access article distributed under the terms of the Creative Commons Attribution License (CC BY). The use, distribution or reproduction in other forums is permitted, provided the original author(s) and the copyright owner(s) are credited and that the original publication in this journal is cited, in accordance with accepted academic practice. No use, distribution or reproduction is permitted which does not comply with these terms. 